\title{
Chagas disease: a report of 17 suspected cases in Japan, 2012-2017
}

\author{
Kazuo Imai ${ }^{1}$, Kazuhisa Misawa ${ }^{2}$, Morichika Osa ${ }^{2}$, Norihito Tarumoto ${ }^{1}$, Jun Sakai ${ }^{1}$, Kei Mikita ${ }^{3}$, Yusuke Sayama ${ }^{4}$, \\ Yuji Fujikura ${ }^{2}$, Akihiko Kawana ${ }^{2}$, Takashi Murakami ${ }^{5}$, Shigefumi Maesaki ${ }^{1}$, Sachio Miura ${ }^{6}$ and Takuya Maeda ${ }^{5^{*}}$ (D)
}

\begin{abstract}
Background: There are no reports on the prevalence of Chagas disease in Japan. Furthermore, screening programs and access to diagnosis and treatment have not been established. This study aimed to clarify the prevalence of Chagas disease among suspected cases in Japan and provide the reference data required for disease control.

Methods: Seventeen patients with suspected Chagas disease in Japan between 2012 and 2017 were included in the study. Patients were diagnosed with Chagas disease based on the two different serological tests for antibodies to Trypanosoma cruzi. Real-time polymerase chain reaction assay and blood culture techniques were performed to confirm T. cruzi parasitemia.

Results: Of the 17 patients, 11 (64.7\%) were immigrants from Latin America. Ultimately, 6 patients (35.3\%) were diagnosed with Chagas disease. Of these 6 patients, median age was 53.5 years, 5 patients were immigrants from Latin American, and 1 was Japanese who had a congenital infection. T. cruzi parasitemia was confirmed in 4 patients (66.7\%), and 5 (83.3\%) were in the chronic phase (Chagas cardiomyopathy, 4; megacolon, 1). Two patients (33.3\%) commenced benznidazole treatment.

Conclusion: Our study showed that some patients of Chagas disease living in Japan are already in the chronic phase at diagnosis because of substantial diagnostic delays. Further epidemiological studies on the prevalence of Chagas disease and systematic screening programs for the Latin American population are needed.
\end{abstract}

Keywords: Chagas disease, Immigrants, Epidemiology, Cardiomyopathy, Japan

\section{Background}

The epidemiology of Chagas disease, caused by the parasite Trypanosoma cruzi, has radically changed with the increasing numbers of immigrants from Latin America, where the disease is endemic. Approximately 250,000 immigrants from Latin America are living in Japan, and in 2010, it was estimated that over 3000 immigrants may have latent Chagas disease infection [1]. In endemic areas, the main route of transmission is by an insect vector known as Triatominae (kissing bugs). Imported cases can potentially spread the infection via non-vector-borne routes such as blood transfusion, organ transplantation, and mother-to-child transmission. In fact, cases of local transmission in non-endemic countries have been

\footnotetext{
*Correspondence: t_maeda@saitama-med.ac.jp

${ }^{5}$ Department of Microbiology, Saitama Medical University, 38 Morohongo,

Moroyama-machi, Iruma-Gun, Saitama 350-0495, Japan

Full list of author information is available at the end of the article
}

described worldwide [2]. The control of Chagas disease is a challenge that requires continuous public health programs.

An epidemiological study found that the prevalence of Chagas disease was $0.017 \%$ among 18,076 blood donors who were at risk of Chagas disease in Japan [3]. Asymptomatic carriers among donors born in endemic areas and cases of congenital Chagas disease have been reported in Japan [4]. The present study aimed to clarify the prevalence of Chagas disease among suspected cases in Japan as a preliminary investigation, and highlights the importance of identifying the clinical characteristics of patients, especially in non-endemic countries.

\section{Material and methods}

Subjects were 17 patients with suspected Chagas disease based on clinical findings (cardiomyopathy, with baseline electrocardiogram or echocardiography abnormalities;

(c) The Author(s). 2019 Open Access This article is distributed under the terms of the Creative Commons Attribution 4.0 International License (http://creativecommons.org/licenses/by/4.0/), which permits unrestricted use, distribution, and reproduction in any medium, provided you give appropriate credit to the original author(s) and the source, provide a link to the Creative Commons license, and indicate if changes were made. The Creative Commons Public Domain Dedication waiver (http://creativecommons.org/publicdomain/zero/1.0/) applies to the data made available in this article, unless otherwise stated. 
gastrointestinal disorders, megacolon, or megaesophagus) and life history (resident in Japan; those with a travel history to Latin America, those born or raised in Latin America, and those whose mother was born or raised in Latin America) from 2012 to 2017. Chagas disease was confirmed with two different serological tests for antibodies to $T$. cruzi. Specifically, the first serological screening was performed using an immunochromatographic test (ICT; Trypanosoma Detect ${ }^{\mathrm{Tx}}$ Rapid Test, InBios International Inc., Seattle, WA) according to the manufacturer's protocol. Positive results were subsequently confirmed via an enzymelinked immunosorbent assay (ELISA; Chagas Detect ${ }^{\mathrm{Tn}}$ Fast ELISA, InBios). Additionally, real-time polymerase chain reaction assay was used to detect the presence of T. cruzi DNA in blood samples [5]. Parasitological diagnosis using the blood culture technique for T. cruzi was also performed.

\section{Results}

Clinical characteristics of the patients and the results of diagnostic tests are summarized in Table 1. Median age of the 17 patients was 50 years; among them, 11 patients $(64.7 \%)$ were immigrants from Latin America (Brazil, 8; Peru, 1; Bolivia, 1) while 6 (35.3\%) were Japanese patients suspected of having $T$. cruzi infection based on either travel history (Ecuador, 1; Latin American countries, 3), birthplace (Peru, 1), or potential mother-to-child infection (Japan, 1). Of the 17 patients, 11 (64.7\%) had cardiac disorders including arrhythmia, heart failure, myocarditis, and cardiomyopathy, and 1 (5.9\%) had megacolon.

Samples from 6 patients (35.3\%) were positive on both serological tests, and the patients were subsequently diagnosed with Chagas disease. Of these 6 patients, 4 (66.7\%) had T. cruzi DNA in whole blood samples in the range 0.1-3.2 parasites $/ \mathrm{mL}$. Blood cultures of samples from 2 patients (33.3\%) were also positive. The median age of the patients with confirmed Chagas disease was 53.5 years; 5 patients were immigrants from Latin America (Brazil, 3; Bolivia, 2), and 1 was Japanese. This patient had a congenital infection and was born in Japan to a Bolivian mother; his mother was diagnosed with Chagas disease at the same time [4]. Among the clinical findings, chronic-phase Chagas disease was diagnosed in 5 patients $(83.3 \%)$, while the phase could not be determined in 1 asymptomatic patient. Chagas cardiomyopathy was present in 4 patients $(66.7 \%)$ and megacolon in 1 patient (16.6\%). Factors other than Chagas that contributed to the cardiac and gastrointestinal disorders were excluded. Benznidazole, used for the treatment of Chagas disease at our hospitals, was initiated in 2 patients (33.3\%).

\section{Discussion}

Our study provides the first insight into the population characteristics of patients with Chagas disease in Japan. Surprisingly, up to $83.3 \%$ of patients with Chagas disease developed chronic complications, including a patient infected by mother-to-child transmission. The most recent series of reports on chronic Chagas disease in non-endemic countries show that mean ages are in the range 35-41 years, $78.9-97.0 \%$ of cases originate in Bolivia, and $18.6-49.0 \%$ of patients have Chagas cardiomyopathy at the initial diagnosis [6-11]. The clinical profiles including the diagnosis of younger patients and lower rates of complications differed from our results. These differences could reflect the substantial delays in the diagnosis of Chagas disease in Japan, which are influenced by the following factors: Most patients are in the asymptomatic intermediate phase of Chagas disease. Physicians are often not sufficiently trained to recognize this disease in non-endemic countries, and the lack of awareness can lead to missed diagnostic opportunities. Active screening programs for high-risk populations in Japan are therefore required to enable early diagnosis and treatment strategies for Chagas disease. In the past decade, to prevent transmission by blood transfusion, a questionnaire has been used to screen Latin Americans who choose to donate blood in Japan. However, this system does not enable early diagnosis and treatment of patients with Chagas disease [3]. Moreover, there are unfortunately no screening programs for high-risk populations including organ transplant patients, pregnant women, and neonates in Japan.

Based on the relatively high prevalence $(>0.05 \%)$ of Chagas disease in European countries, systemic screening for Chagas disease in asymptomatic Latin American residents is considered a cost-effective public health strategy [12]. Therefore, careful consideration based on accurate surveillance is needed to establish an active screening strategy in Japan. Although the prevalence of Chagas disease among at-risk blood donors was previously reported to be $0.017 \%$, this was not necessarily reflective of the prevalence because of sample selection bias [3]. Legal authorities for Chagas disease reporting systems can be helpful for obtaining information about the prevalence and clinical characteristics and contributing to the public policy-making process. In addition, it is desirable that the target population of active screening be covered by national health insurance with regard to the return on investment of public health programs.

Anti-trypanosomal treatments for patients with chronic Chagas disease are controversial, but the early treatment of asymptomatic patients is considered essential to prevent local transmission and Chagas cardiomyopathy. 


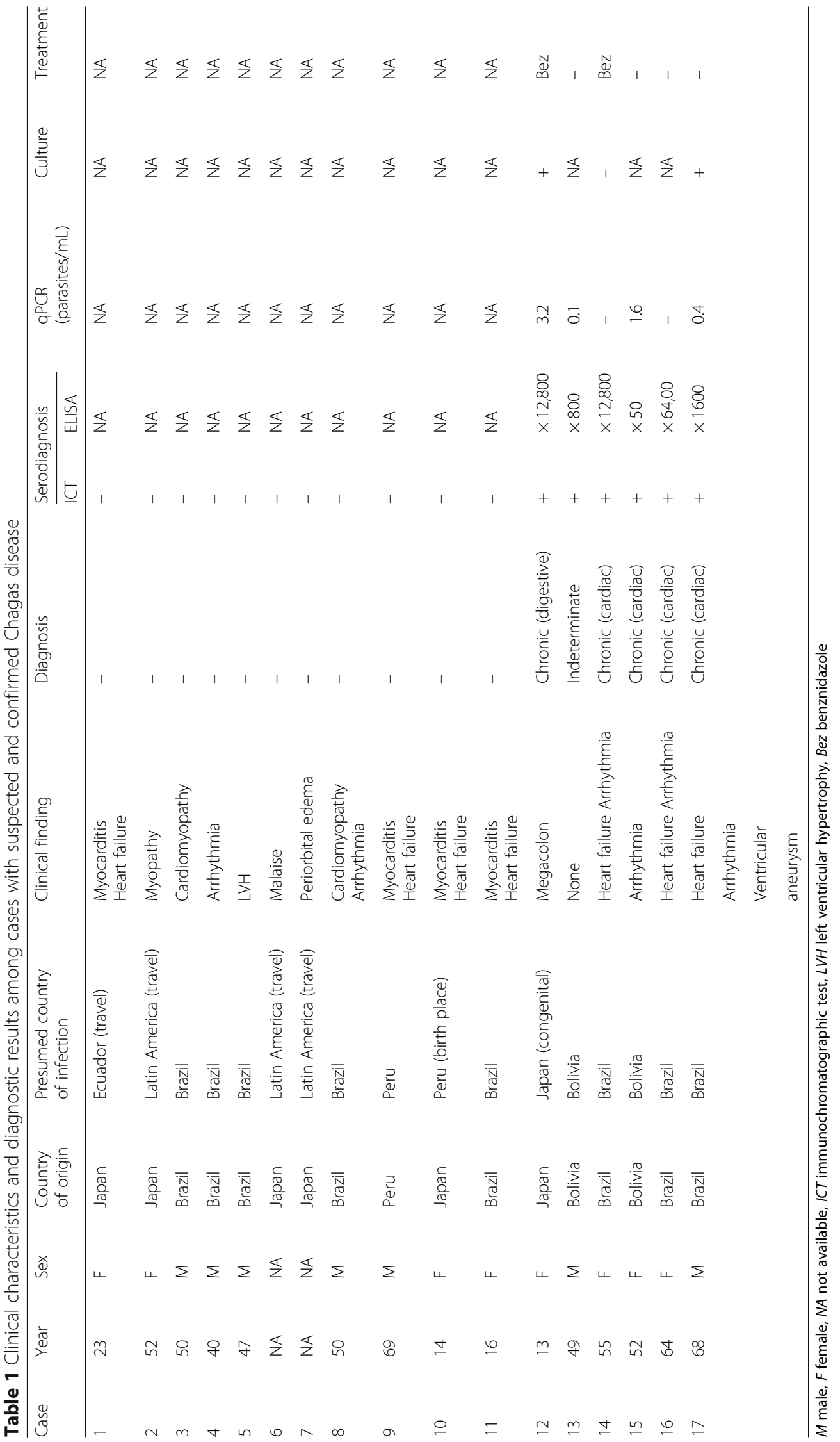


Furthermore, the risk of drug toxicity is higher in older individuals than in younger adults; hence, antitrypanosomal treatments for patients older than 50 years are not recommended [13]. The Benznidazole Evaluation for Interrupting Trypanosomiasis (BENEFIT) trial, which was the first randomized double-blind controlled clinical trial to investigate the role of benznidazole in patients with chronic Chagas cardiomyopathy, showed that antitrypanosomal treatment for patients with Chagas cardiomyopathy did not reduce clinical cardiac deterioration [14]. Therefore, this study points to the importance of early diagnosis and treatment of patients with asymptomatic Chagas disease to prevent the progression of cardiomyopathy. Early diagnosis and treatment also contribute to the prevention of vertical transmission. Serum parasite load is significantly reduced in patients treated with antitrypanosomal drugs [14], and several reports have shown that anti-trypanosomal treatment of infected women of reproductive age can also be an effective strategy to prevent congenital transmission of Chagas disease $[15,16]$.

Our results do not accurately reflect the full clinical characteristics and prevalence of Chagas disease across Japan because of sample selection bias and the small sample size. However, our study showed that patients with Chagas disease living in Japan may miss opportunities for treatment because of substantial diagnostic delays. A large sample size will be required to obtain a more accurate evaluation of the prevalence of Chagas disease and an economic evaluation of systematic screening programs for the Latin American population.

\section{Conclusions}

This report represents the first step towards an epidemiological study of Chagas disease in Japan. Further largescale epidemiological studies on the prevalence of Chagas disease may help to determine the need for systematic screening programs for the Latin American population.

\section{Acknowledgements}

Not applicable.

\section{Authors' contributions}

$\mathrm{KI}$, SMi, and TMa conceived and designed the study. KI, YS, KM, MO, NT, JS, and KM performed the experiments. YF, AK, TMu, SMa, SMi, and TMa organized the recruitment and enrollment of patients. KI, SMi, and TMa analyzed and interpreted the data and wrote the manuscript. TMa critically revised the manuscript. All authors read and approved the final manuscript.

\section{Funding}

Not applicable.

\section{Availability of data and materials}

Data are available from the corresponding author on reasonable request.

\section{Ethics approval and consent to participate}

The design and protocol of this study conformed with the Helsinki Declaration and was approved by the Institutional Ethics Committee (approval number: 869; Saitama Medical University, 2911; National Defense Medical College).
Consent for publication

Not applicable.

\section{Competing interests}

The authors declare that they have no competing interests.

\section{Author details}

'Department of Infectious Disease and Infection Control, Saitama Medical University, Saitama, Japan. ${ }^{2}$ Division of Infectious Diseases and Pulmonary Medicine, Department of Internal Medicine, National Defense Medical College, Saitama, Japan. ${ }^{3}$ Department of Infectious Diseases, Keio University School of Medicine, Tokyo, Japan. ${ }^{4}$ Central Blood Institute, Blood Service Headquarters, Japanese Red Cross Society, Tokyo, Japan. ${ }^{5}$ Department of Microbiology, Saitama Medical University, 38 Morohongo, Moroyama-machi, Iruma-Gun, Saitama 350-0495, Japan. ${ }^{6}$ Tokyo College of Medical Technology, Tokyo, Japan.

Received: 26 March 2019 Accepted: 28 May 2019

Published online: 13 June 2019

\section{References}

1. Coura JR, Vinas PA. Chagas disease: a new worldwide challenge. Nature 2010;465(7301):S6-7

2. Flores-Chavez M, Fernandez B, Puente S, Torres P, Rodriguez M, Monedero C, Cruz I, Garate T, Canavate C. Transfusional chagas disease: parasitological and serological monitoring of an infected recipient and blood donor. Clin Infect Dis. 2008;46(5):e44-7.

3. Sayama Y, Furui Y, Takakura A, Ishinoda M, Matsumoto C, Taira R, Igarashi S, Momose S, Matsubayashi K, Uchida S, Hino S, Nagai T, Satake M.

Seroprevalence of Trypanosoma cruzi infection among at-risk blood donors in Japan. Transfusion. 2019;59(1):287-94.

4. Imai K, Maeda T, Sayama Y, Mikita K, Fujikura Y, Misawa K, Nagumo M, Iwata O, Ono T, Kurane I, et al. Mother-to-child transmission of congenital Chagas disease, Japan. Emerg Infect Dis. 2014:20(1):146-8.

5. Piron M, Fisa R, Casamitjana N, Lopez-Chejade P, Puig L, Verges M, Gascon J, Gomez I, Prat J, Portus M, Sauleda S. Development of a real-time PCR assay for Trypanosoma cruzi detection in blood samples. Acta Trop. 2007;103(3):195-200.

6. Salvador F, Trevino B, Sulleiro E, Pou D, Sanchez-Montalva A, Cabezos J, Soriano A, Serre N, Gomez I, Prat J, Pahissa A, et al. Trypanosoma cruzi infection in a non-endemic country: epidemiological and clinical profile. Clin Microbiol Infect. 2014;20(7):706-12.

7. Lescure FX, Paris L, Elghouzzi MH, Le Loup G, Develoux M, Touafek F, Mazier D, Pialoux G. Experience of targeted screening of Chagas disease in lle-deFrance. Bull Soc Pathol Exot. 2009;102(5):295-9.

8. Perez-Ayala A, Perez-Molina JA, Norman F, Navarro M, Monge-Maillo B, DiazMenendez M, Peris-Garcia J, Flores M, Canavate C, Lopez-Velez R. Chagas disease in Latin American migrants: a Spanish challenge. Clin Microbiol Infect. 2011;17(7):1108-13.

9. Valerio-Sallent L, Roure S, Basile L, Ballesteros LA, Sabria M, Rodrigo C. Grupo Metropolitano de estudio del Chagas. [A clinical and epidemiological study of the Trypanosoma cruzi infected population in the north metropolitan area of Barcelona]. Rev Clin Esp. 2012;212(7):329-36.

10. Jackson Y, Chappuis F. Chagas disease in Switzerland: history and challenges. Euro Surveill. 2011;16(37).

11. Ramos JM, Torrus D, Amador C, Jover F, Perez-Chacon F, Ponce Y, Arjona FJ Caro E, Martinez-Peinado C, Gallegos I, et al. Multicenter epidemiological and clinical study on imported Chagas diseases in Alicante, Spain. Pathog Glob Health. 2012;106(6):340-5.

12. Requena-Mendez $A$, Bussion $S$, Aldasoro $E$, Jackson $Y$, Angheben A, Moore D, Pinazo MJ, Gascon J, Munoz J, Sicuri E. Cost-effectiveness of Chagas disease screening in Latin American migrants at primary health-care centres in Europe: a Markov model analysis. Lancet Glob Health. 2017:5(4):e439-e47.

13. Bern C, Montgomery SP, Herwaldt BL, Rassi A Jr, Marin-Neto JA, Dantas RO, Maguire $\mathrm{JH}$, Acquatella $\mathrm{H}$, Morillo $\mathrm{C}$, Kirchhoff $\mathrm{LV}$, et al. Evaluation and treatment of chagas disease in the United States: a systematic review. JAMA. 2007;298(18):2171-81.

14. Morillo CA, Marin-Neto JA, Avezum A, Sosa-Estani S, Rassi A Jr, Rosas F, Villena E, Quiroz R, Bonilla R, Britto C, et al. Randomized trial of benznidazole for chronic Chagas' cardiomyopathy. N Engl J Med. 2015;373(14):1295-306. 
15. Alvarez MG, Vigliano C, Lococo B, Bertocchi G, Viotti R. Prevention of congenital Chagas disease by benznidazole treatment in reproductive-age women. An observational study. Acta Trop. 2017;174:149-52.

16. Fabbro DL, Danesi E, Olivera V, Codebo MO, Denner S, Heredia C, Streiger $M$, Sosa-Estani S. Trypanocide treatment of women infected with Trypanosoma cruzi and its effect on preventing congenital Chagas. PLoS Negl Trop Dis. 2014;8(11):e3312

\section{Publisher's Note}

Springer Nature remains neutral with regard to jurisdictional claims in published maps and institutional affiliations.

Ready to submit your research? Choose BMC and benefit from:

- fast, convenient online submission

- thorough peer review by experienced researchers in your field

- rapid publication on acceptance

- support for research data, including large and complex data types

- gold Open Access which fosters wider collaboration and increased citations

- maximum visibility for your research: over $100 \mathrm{M}$ website views per year

At $B M C$, research is always in progress.

Learn more biomedcentral.com/submissions 